\title{
Significance of age-associated quality of life in patients with stage IV breast cancer who underwent endocrine therapy in Japan
}

\author{
KOJI TAKADA ${ }^{1}$, SHINICHIRO KASHIWAGI ${ }^{1}$, YUKA ASANO ${ }^{1}$, WATARU GOTO ${ }^{1}$, \\ TAMAMI MORISAKI ${ }^{1}$, KATSUYUKI TAKAHASHI ${ }^{2}$, MASATSUNE SHIBUTANI ${ }^{3}$, RYOSUKE AMANO ${ }^{4}$, \\ TSUTOMU TAKASHIMA ${ }^{1}$, SHUHEI TOMITA ${ }^{2}$, KOSEI HIRAKAWA ${ }^{1,3}$ and MASAICHI OHIRA ${ }^{1,3}$ \\ Departments of ${ }^{1}$ Breast and Endocrine Surgery, ${ }^{2}$ Pharmacology, ${ }^{3}$ Gastrointestinal Surgery and \\ ${ }^{4}$ Hepato-Biliary-Pancreatic Surgery, Osaka City University Graduate School of Medicine, Osaka 545-8585, Japan
}

Received September 30, 2019; Accepted April 1, 2020

DOI: $10.3892 / 01.2020 .12041$

\begin{abstract}
Currently, when determining treatment regimens, there is an emphasis on the quality of life (QOL), in addition to treatment efficacy. Especially in hormone receptor-positive breast cancer with distant metastases, unless death is imminent, a common first-line treatment is endocrine therapy, which has fewer side effects. In the present study, the differences in QOL were evaluated based on the age and prognostic indicators of 46 patients with hormone receptor-positive breast cancer with distant metastases (stage IV), who received first-line endocrine therapy at the Osaka City University Hospital (Osaka, Japan) between November 2007 and November 2016. QOL score before and after endocrine therapy was retrospectively analyzed, using the Quality of Life Questionnaire for Cancer Patients Treated with Anti-Cancer Drugs-Breast (QOL-ACD-B). There was no significant association between age and any of the clinicopathological features investigated. However, the QOL score of the elderly patient group was significantly higher compared with that of the younger group in the 'Satisfaction with treatment and coping with disease' subcategory $(\mathrm{P}=0.008)$. The QOL score of the younger age group in the same subcategory was significantly improved by the treatment $(\mathrm{P}=0.013)$. The patients that had an increased overall QOL score 3 months after treatment initiation had a significant extension of progression-free survival (PFS) rate compared to the patients with decreased or no change in $\mathrm{QOL}(\mathrm{P}=0.032)$. In conclusion, psychological stress was more prominent in younger patients with stage IV breast cancer treated with hormonal therapy compared with elderly patients.
\end{abstract}

Correspondence to: Dr Shinichiro Kashiwagi, Department of Breast and Endocrine Surgery, Osaka City University Graduate School of Medicine, 1-4-3 Asahi-machi, Abeno-ku, Osaka 545-8585, Japan

E-mail: spqv9ke9@view.ocn.ne.jp

Key words: quality of life, hormone receptor-positive breast cancer, distant metastases, prognosis, endocrine therapy
Importantly, improving QOL within the 3 months after treatment initiation could lead to longer PFS rate.

\section{Introduction}

Patients with cancer are subjected to numerous stressors, caused not only by the cancer itself but also by the subsequent treatment. These stressors include physical, mental and social factors that can collectively affect the patient's quality of life (QOL). The World Health Organization has included QOL as a fundamental concept in the definition of 'health', which is a state of complete physical, mental, and social well-being, and not merely the absence of disease or infirmity (1).

Currently, the impact on QOL is an important factor to consider, in addition to treatment efficacy, when determining treatment regimens. Previous studies in various types of cancer, such as colorectal and non-small cell lung cancer, have reported that QOL affects the prognosis of patients (2-5). Most of these studies included patients with cancer and distant metastases, who had received chemotherapy, and reported that chemotherapy-associated side effects caused deterioration in QOL. However, in hormone receptor-positive breast cancer with distant metastases, unless death is imminent, a common first-line treatment is endocrine therapy (6). Even though this treatment is not curative, it is chosen because of its positive impact on QOL (fewer treatment-associated side effects), as well as patient prognosis.

As the average life expectancy and the number of elderly breast cancer cases have increased, the evaluation of QOL in the elderly patients has become more important. In the present study, the differences in QOL were evaluated based on the age and prognostic indicators of patients with breast cancer and distant metastases (stage IV), who received first-line endocrine therapy.

\section{Patients and methods}

Study design. In this retrospective cohort study, patients treated with first-line endocrine therapy, after being diagnosed with hormone receptor-positive breast cancer with distant metastases at the Osaka City University Hospital between November 2007 and November 2016, were selected. The study was conducted at Osaka City University Graduate School of 
Medicine, according to the Reporting Recommendations for Tumor Marker Prognostic Studies (REMARK) guidelines and following a retrospectively written research, pathological evaluation, and statistical plan (7). The study protocol was approved by the Ethics Committee of Osaka City University (approval no. 926) and written informed consent was obtained from all patients.

Patient background. Forty-six patients were treated with first-line endocrine therapy after being diagnosed with hormone receptor-positive breast cancer [estrogen receptor (ER) and/or progesterone receptor (PgR)-positive] with distant metastases. All patients were pathologically diagnosed with breast cancer, and the expression levels of ER, PgR, human epidermal growth factor receptor 2 (HER2), and Ki67 were confirmed by immunostaining. Staging was evaluated by ultrasonography (US), computed tomography (CT), and bone scintigraphy. Patients with dementia were excluded. All patients were prescribed hormonal therapy drugs as outpatients. Patients were required to visit the hospital 3 months after treatment initiation for physical examinations, US and CT to determine the therapeutic effects, which were evaluated according to the Response Evaluation Criteria in Solid Tumors (8).

Study outcomes. To determine the objective response rate (ORR), 'responder' was defined as a patient showing a clinical partial response (cPR) or a clinical complete response (cCR); and 'non-responder' was defined as a patient with a clinical stable disease (cSD) or a clinical progressive disease (cPD). Progression-free survival (PFS) rate was defined as the period from the treatment initiation to the time when CPD was detected or to the date of death. Overall survival (OS) rate was defined as the period from the treatment initiation to the date of death or the censor date at the end of the study period, if still alive. All patients underwent follow-up physical examinations every 3 months, and US and CT every 6 months.

QOL evaluation. The widely accepted general QOL scale for cancer in Japan is based on the Quality of Life Questionnaire for Cancer Patients Treated with Anti-Cancer Drugs (QOL-ACD), developed by Kurihara et al (9) and supported by the Japanese Ministry of Health and Welfare (Tokyo, Japan). Specialized QOL scales for different cancer types have been developed. In the present study, the scale developed for breast cancer was used, known as QOL-ACD-B (10).

Briefly, QOL-ACD-B consists of 18 criteria, each of which is evaluated on a scale from 1 to 5 ( 1 being the worst and 5 being the best). The 18 criteria are grouped into 4 subcategories: 'Physical symptoms and pain' (6 criteria), 'Satisfaction with treatment and coping with disease' (4 criteria), 'Side effects of treatment' ( 4 criteria), and 'Dress, sexual aspect, other' (4 criteria) (Table SI). The scores of the entire QOL-ACD-B and each subcategory are calculated by subtracting 1 from the average of the criteria evaluated and multiplied by 25 ; thus, the minimum value is 0 and the maximum value is 100 .

QOL at the time of diagnosis and 3 months after treatment was retrospectively evaluated. Changes in the overall QOL and per subcategory 3 months after treatment initiation were also calculated based on age. In addition, the association of
Table I. Clinicopathological characteristics of 46 patients with stage IV breast cancer receiving first-line endocrine therapy.

\begin{tabular}{|c|c|}
\hline Parameters & Data \\
\hline Age, years (range) & $65(40-89)$ \\
\hline Tumor size, mm (range) & $39.4(11.8-146.3)$ \\
\hline \multicolumn{2}{|l|}{ Skin infiltration, $\mathrm{n}(\%)$} \\
\hline Negative & $13(28.3)$ \\
\hline Positive & $33(71.7)$ \\
\hline \multicolumn{2}{|l|}{ Lymph node metastasis, n (\%) } \\
\hline NO & $7(15.2)$ \\
\hline $\mathrm{N} 1$ & $9(19.6)$ \\
\hline $\mathrm{N} 2$ & $13(28.3)$ \\
\hline N3 & $17(37.0)$ \\
\hline \multicolumn{2}{|l|}{ No. of metastatic organs, $\mathrm{n}(\%)$} \\
\hline 1 & $23(50.0)$ \\
\hline 2 & $15(32.6)$ \\
\hline 3 & $7(15.2)$ \\
\hline 4 & $1(2.2)$ \\
\hline \multicolumn{2}{|l|}{ Site of metastasis, $\mathrm{n}(\%)$} \\
\hline Lung & $25(54.3)$ \\
\hline Bone & $31(67.4)$ \\
\hline Liver & $7(15.2)$ \\
\hline Brain & $1(2.2)$ \\
\hline Skin & $1(2.2)$ \\
\hline Distant lymph node & $13(28.3)$ \\
\hline \multicolumn{2}{|l|}{ HER $2, \mathrm{n}(\%)$} \\
\hline Negative & $44(95.7)$ \\
\hline Positive & $2(4.3)$ \\
\hline \multicolumn{2}{|l|}{$\mathrm{Ki} 67, \mathrm{n}(\%)$} \\
\hline Negative & $28(60.9)$ \\
\hline Positive & $18(39.1)$ \\
\hline \multicolumn{2}{|l|}{ Endocrine therapy, n (\%) } \\
\hline LH-RH agonist + TAM & $6(13.0)$ \\
\hline TAM & $1(2.2)$ \\
\hline LET & $28(60.9)$ \\
\hline ANA & $10(21.7)$ \\
\hline EXE & $1(2.2)$ \\
\hline \multicolumn{2}{|l|}{ Combined radiation therapy, $\mathrm{n}(\%)$} \\
\hline No & $43(93.5)$ \\
\hline Yes & $3(6.5)$ \\
\hline \multicolumn{2}{|l|}{$\begin{array}{l}\text { ORR } 3 \text { months after starting } \\
\text { treatment, } \mathrm{n}(\%)\end{array}$} \\
\hline Non-responders & $18(39.1)$ \\
\hline Responders & $28(60.9)$ \\
\hline \multicolumn{2}{|l|}{ ORR, n (\%) } \\
\hline Non-responders & $12(26.1)$ \\
\hline Responders & $34(73.9)$ \\
\hline QOL-ACD-B before treatment (range) & $90.63(71.88-98.44)$ \\
\hline $\begin{array}{l}\text { Change in QOL (First } 3 \text { months after } \\
\text { treatment initiation) (range) }\end{array}$ & $3.13(-21.88-14.06)$ \\
\hline $\begin{array}{l}\text { QOL-ACD-B ( } 3 \text { months after treatment } \\
\text { initiation) (range) }\end{array}$ & $93.75(62.50-98.44)$ \\
\hline
\end{tabular}

HER, human epidermal growth factor receptor; LH-RH, luteinizing hormone-releasing hormone; TAM, tamoxifen; LET, letrozole; ANA, anastrozole; EXE, exemestane; ORR, objective response rate; QOL, quality of life; QOL-ACD-B, Questionnaire for Cancer Patients Treated with Anti-Cancer Drugs-Breast. 
Table II. Association of clinicopathological features with age.

Age, n (\%)

Parameters

Younger $(\leq 65$ years $)(n=23)$

Elder ( $>65$ years) $(n=23)$

P-value

Tumor size, $\mathrm{mm}$

$\leq 39.4$

$12(52.2)$

$11(47.8)$

$>39.4$

$11(47.8)$

$12(52.2)$

0.774

Skin infiltration

Negative

5 (21.7)

8 (34.8)

Positive

18 (78.3)

15 (65.2)

0.337

Lymph node metastasis

Negative

4 (17.4)

$3(13.0)$

Positive

19 (82.6)

$20(87.0)$

0.690

No. of metastatic organs

$\leq 2$

19 (82.6)

19 (82.6)

$\geq 3$

4 (17.4)

4 (17.4)

1.000

Lung metastasis

Negative

8 (34.8)

$13(56.5)$

Positive

$15(65.2)$

$10(43.5)$

0.145

Bone metastasis

Negative

$10(43.5)$

$5(21.7)$

13 (56.5)

18 (78.3)

0.121

Liver metastasis

Negative

19 (82.6)

$20(87.0)$

Positive

4 (17.4)

$3(13.0)$

0.690

Distant lymph node metastasis

Negative

$19(82.6)$

$14(60.9)$

4 (17.4)

9 (39.1)

0.106

Ki67

Negative

$13(56.5)$

$15(65.2)$

$10(43.5)$

8 (34.8)

0.556

Combined radiation therapy

No

$20(87.0)$

$23(100.0)$

Yes

3 (13.0)

$0(0.0)$

0.076

ORR (3 months after treatment initiation)

Non-responders

8 (34.8)

$10(43.5)$

$15(65.2)$

$13(56.5)$

0.556

ORR

Non-responders

Responders

$17(73.9)$

$17(73.9)$

1.000

ORR, overall response rate.

QOL scores with patient clinicopathological factors and effect on prognosis were analyzed.

Statistical analysis. Statistical analyses were performed using the JMP software package version 10 (SAS Institute, Inc.). Student's t-test was used for the comparison of the score distributions. The associations between variables were examined using the $\chi^{2}$ test. Regarding age, the patients were categorized into the elderly and the younger age group using the median age (65 years) as the cut-off value for stratification. The Kaplan-Meier method was used to determine PFS rate and OS rate, and the log-rank test was used to compare the survival curves. Hazard ratios (HRs) and 95\% confidence intervals (CIs) were calculated using the Cox proportional-hazards model. Univariate and multivariate analyses were performed using the Cox regression model. $\mathrm{P}<0.05$ was considered to indicate a statistically significant difference. 

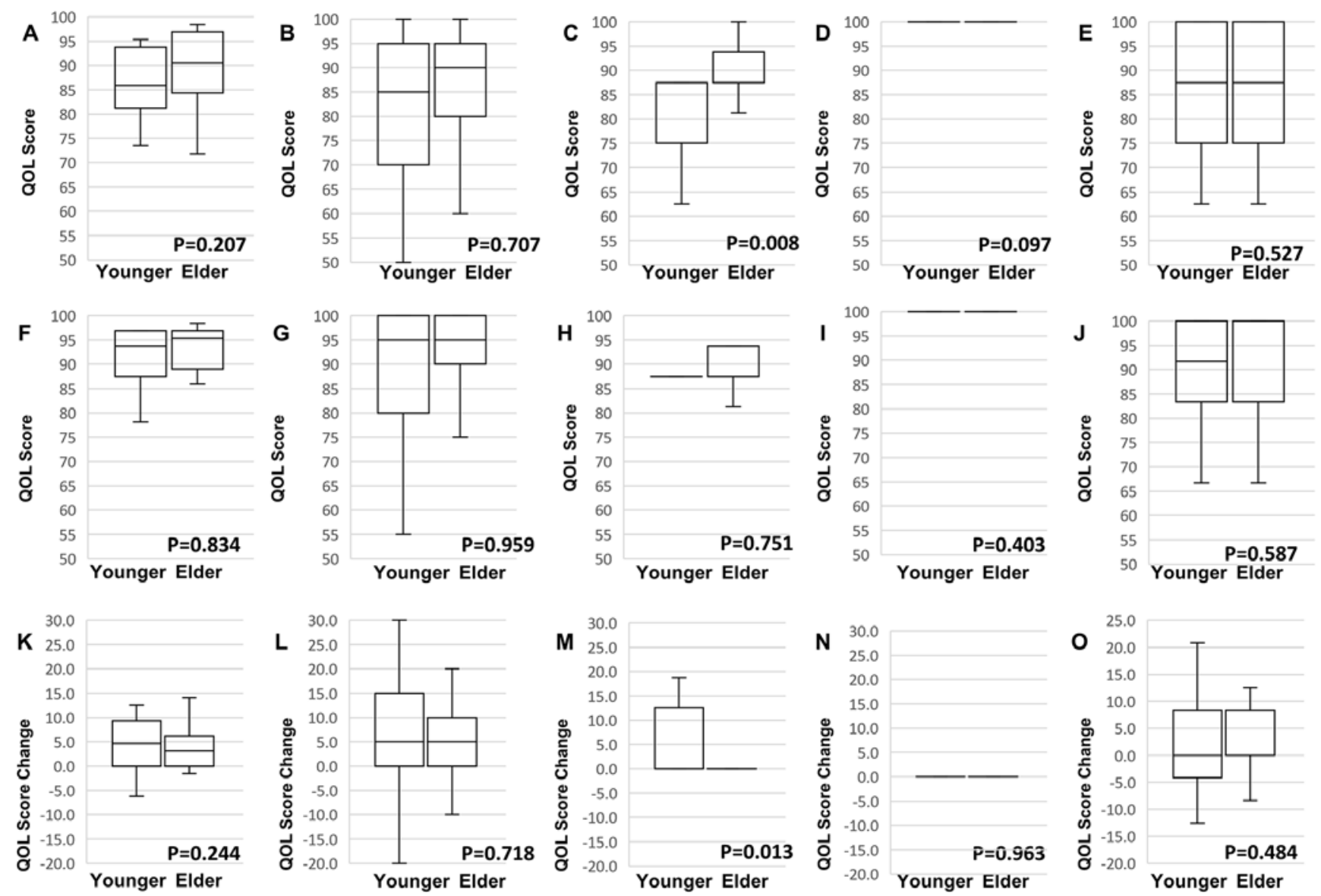

Figure 1. Comparison of overall QOL score and subscales before treatment between the younger and the elder patients using box-plot diagrams: (A) Whole QOL, (B) 'Physical symptoms and pain', (C) 'Satisfaction to treatment and coping with disease', (D) 'Side effects of treatment', (E) 'Dress, sexual aspect, other'. Comparison of overall QOL score and subscales at 3 months after treatment initiation between the younger and the elder using box-plot diagrams: (F) Whole QOL, (G) 'Physical symptoms and pain', (H) 'Satisfaction with treatment and coping with disease', (I) 'Side effects of treatment', (J) 'Dress, sexual aspect, other'. Comparison of change in overall QOL score and subscales during 3 months of treatment between the younger and the elder using box-plot diagrams: (K) Whole QOL, (L) 'Physical symptoms and pain', (M) 'Satisfaction with treatment and coping with disease', (N) 'Side effects of treatment', (O) 'Dress, sexual aspect, other'. QOL, quality of life.

\section{Results}

Clinicopathological features. The clinicopathological features of 46 patients who were diagnosed with hormone receptor-positive breast cancer with distant metastases and treated with first-line endocrine therapy are detailed in Table I. The median age at treatment initiation was 65 years (range, 40-89 years), and tumor diameter was $39.4 \mathrm{~mm}$ (range, 11.8-146.3 mm). The median overall follow-up time since treatment initiation was 1,272 days (range, 120-3,271 days).

Thirty-three patients $(71.7 \%)$ had skin infiltration and 39 patients $(84.8 \%)$ were diagnosed with lymph node metastases. Overall, 23 patients $(50.0 \%)$ had distant metastasis to a single organ, whereas the remaining 23 patients $(50.0 \%)$ had distant metastases to multiple organs. The sites of metastasis included the lungs (25 patients; $54.3 \%$ ), bones (31 patients; $67.4 \%$ ), liver (7 patients; $15.2 \%$ ), brain (1 patient; $2.2 \%$ ), skin (1 patient; $2.2 \%$ ), and distant lymph nodes (13 patients; 28.3\%). While tamoxifen in conjunction with luteinizing hormone-releasing hormone (LH-RH) agonist was offered to 6 patients (13.0\%), single-agent treatment was prescribed with the following drugs: Tamoxifen (1 patient; $2.2 \%$ ), letrozole (28 patients; 60.9\%), anastrozole
(10 patients; $21.7 \%$ ), and exemestane (1 patient; $2.2 \%$ ). In all cases with bone metastases, zoledronic acid or denosumab was used in combination with endocrine therapy; 3 of these patients received the drugs in combination with radiation therapy. Two cases (4.3\%) that were HER2-positive received no anti-HER 2 therapy. None of the cases developed cCR; however, 28 patients $(60.9 \%)$ showed cPR 3 months after treatment initiation, and by the end of the study period, a total of 34 patients $(73.9 \%)$ showed cPR. The median QOL score prior to treatment was 90.63 (range, 71.88-98.44), and 3 months after treatment initiation was 93.75 (range, 62.50-98.44). Overall, 13 cases of mortality were attributed to breast cancer, and no deaths due to other causes were noted.

Differences in clinicopathological features and QOL based on age. There was no significant association between age and any of the clinicopathological features investigated (Table II). Additionally, there was no significant difference in overall QOL prior to treatment based on age (Fig. 1A). However, QOL score was significantly higher among the elderly in the 'Satisfaction with treatment and coping with disease' subcategory ( $\mathrm{P}=0.008$; Fig. 1C). After 3 months of treatment, no 

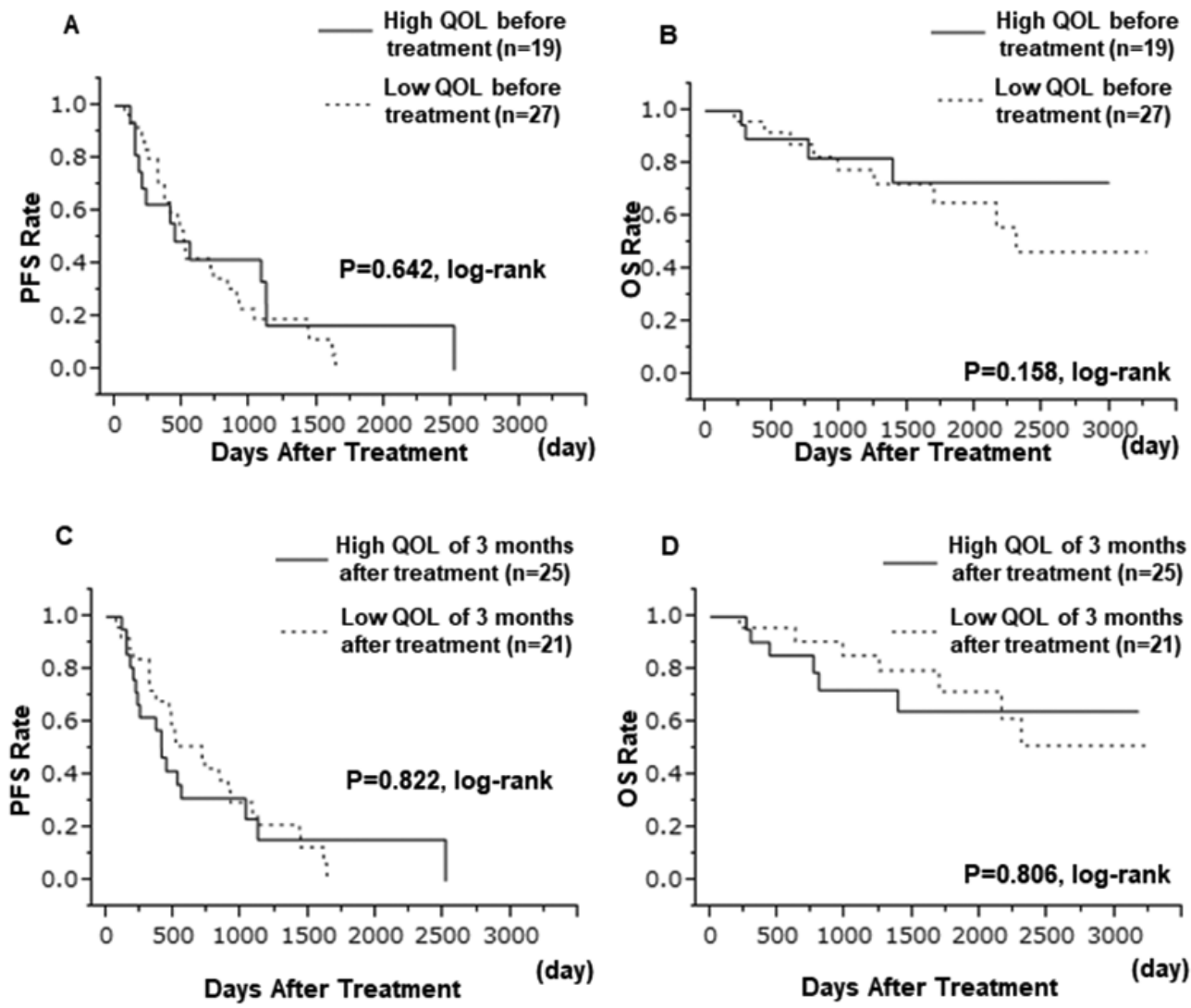

E

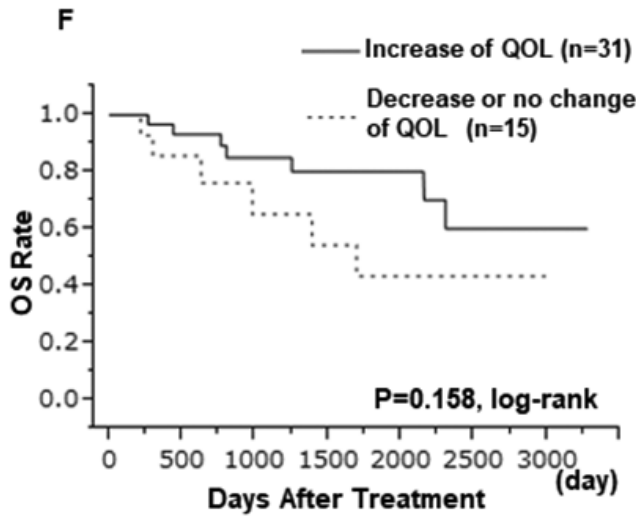

Figure 2. Kaplan-Meier survival curves based on QOL score before treatment: (A) PFS, (B) OS; based on QOL score at 3 months after treatment initiation (C) PFS, (D) OS; based on the change in QOL score during 3 months of treatment: (E) PFS, (F) OS. QOL, quality of life; PFS, progression-free survival; OS, overall survival.

association was found between age and overall QOL or any of the subcategories (Fig. 1F-J). However, QOL score in the 'Satisfaction with treatment and coping with disease' subcategory was significantly improved by treatment in the younger age group ( $\mathrm{P}=0.013$; Fig. $1 \mathrm{M})$.

Association of $Q O L$ with survival outcomes. Patients were divided into high and low QOL groups, before and at 3 months after treatment initiation; the median QOL score at each time point was used as the cut-off value. Nineteen patients (41.3\%) had high QOL score before treatment, whereas 27 patients (58.7\%) had low QOL score. The pre-treatment QOL score had no significant impact on PFS rate $(\mathrm{P}=0.642)$ and $\mathrm{OS}$ rate $(\mathrm{P}=0.158$; Fig. 2A and $\mathrm{B})$. Three months after treatment initiation, 21 patients (45.7\%) and 25 patients (54.3\%) had low and high QOL score, respectively. Again, no significant impact of QOL was observed on PFS rate $(\mathrm{P}=0.822)$ and $\mathrm{OS}$ rate ( $\mathrm{P}=0.806$; Fig. 2C and D).

The QOL score increased for 31 patients (67.4\%) during the 3 months following treatment initiation; these patients were referred to as the 'increased QOL group'. Conversely, the QOL score decreased or did not change for 15 patients (32.6\%); these patients were referred to as the 'decreased QOL group.' Tumor size was significantly larger and lymph node metastases were more frequently observed in the 'increased QOL group' when compared with the 'decreased QOL group' ( $\mathrm{P}=0.004$ and $\mathrm{P}=0.017$, respectively). Furthermore, in the 'increased QOL group' the ORR was higher 3 months after treatment initiation $(\mathrm{P}=0.007)$, as well as during the treatment period $(\mathrm{P}=0.003)$. The 'increased $\mathrm{QOL}$ group' had a 
Table III. Association of clinicopathological features with change in QOL during treatment.

Change in QOL during treatment, n (\%)

Parameters

Decrease/no change $(n=15)$

Increase $(n=31)$

P-value

Age

$\leq 65$ years

$6(40.0)$

$17(54.8)$

$>65$ years

$9(60.0)$

$14(45.2)$

0.344

Tumor size, $\mathrm{mm}$

$\leq 39.4$

$12(80.0)$

$11(35.5)$

$>39.4$

$3(20.0)$

$20(64.5)$

0.004

Skin infiltration

Negative

$6(40.0)$

7 (22.6)

Positive

$9(60.0)$

$24(77.4)$

0.228

Lymph node metastasis

Negative

$5(33.3)$

2 (6.5)

Positive

$10(66.7)$

$29(93.5)$

0.017

No. of metastatic organs

$12(80.0)$

$26(83.9)$

$\geq 3$

$5(16.1)$

0.752

Lung metastasis

Negative

$8(53.3)$

$13(41.9)$

Positive

7 (46.7)

$18(58.1)$

0.478

Bone metastasis

Negative

$2(13.3)$

13 (41.9)

Positive

13 (86.7)

$18(58.1)$

0.054

Liver metastasis

Negative

$12(80.0)$

$27(87.1)$

Positive

$3(20.0)$

4 (12.9)

0.540

Distant lymph node metastasis

Negative

$11(73.3)$

$22(71.0)$

Positive

4 (26.7)

$9(29.0)$

0.871

Ki67

Negative

7 (46.7)

$21(67.7)$

Positive

8 (53.3)

$10(32.3)$

0.177

Combined radiation therapy

No

$14(93.3)$

$29(93.5)$

1 (6.7)

2 (6.5)

0.979

ORR (3 months after treatment initiation)

$10(66.7)$

8 (25.8)

Non-responders

5 (33.3)

$23(74.2)$

0.007

ORR

Non-responders

$8(53.3)$

4 (12.9)

7 (46.7)

27 (87.1)

0.003

QOL-ACD-B before treatment

Low

5 (33.3)

$22(71.0)$

10 (66.7)

$9(29.0)$

0.015

QOL-ACD-B (3 months after treatment initiation)

Low

7 (46.7)

18 (58.1)

High

8 (53.3)

13 (41.9)

0.478

QOL, quality of life; ORR, overall response rate; QOL-ACD-B, Questionnaire for Cancer Patients Treated with Anticancer Drugs-Breast. 
Table IV. Univariate and multivariate analysis of PFS rate and OS rate of 46 patients with stage IV breast cancer under endocrine therapy.

\begin{tabular}{|c|c|c|c|c|c|c|c|}
\hline \multirow[b]{2}{*}{ Parameter } & \multirow[b]{2}{*}{ Items } & \multicolumn{3}{|c|}{ Univariate analysis } & \multicolumn{3}{|c|}{ Multivariate analysis } \\
\hline & & HR & $95 \% \mathrm{CI}$ & P-value & HR & $95 \% \mathrm{CI}$ & P-value \\
\hline \multicolumn{8}{|l|}{ PFS rate } \\
\hline Age at treatment & $\leq 65 />65$ years & 1.021 & $0.540-1.926$ & 0.948 & & & \\
\hline Tumor size & $\leq 39.4 />39.4 \mathrm{~mm}$ & 0.911 & $0.478-1.748$ & 0.776 & & & \\
\hline Skin infiltration & Negative/positive & 0.618 & $0.314-1.294$ & 0.194 & & & \\
\hline HER2 & Negative/positive & 3.335 & $0.526-11.787$ & 0.169 & & & \\
\hline Ki67 & Negative/positive & 1.832 & $0.923-3.537$ & 0.082 & 1.220 & $0.524-2.652$ & 0.631 \\
\hline Lymph node metastasis & Negative/positive & 0.781 & $0.347-2.088$ & 0.592 & & & \\
\hline No. of metastatic organs & $\leq 2 / \geq 3$ & 1.496 & $0.634-3.126$ & 0.334 & & & \\
\hline Lung metastasis & Negative/positive & 0.533 & $0.277-1.024$ & 0.059 & 0.523 & $0.263-1.042$ & 0.065 \\
\hline Bone metastasis & Negative/positive & 1.722 & $0.878-3.582$ & 0.116 & & & \\
\hline Liver metastasis & Negative/positive & 3.624 & $1.421-8.156$ & 0.009 & 2.636 & $0.882-7.552$ & 0.081 \\
\hline Distant lymph node metastasis & Negative/positive & 1.445 & $0.718-2.768$ & 0.291 & & & \\
\hline Combined radiation therapy & No/yes & 1.852 & $0.295-6.400$ & 0.446 & & & \\
\hline QOL-ACD-B before treatment & Low/high & 0.855 & $0.431-1.631$ & 0.640 & & & \\
\hline $\begin{array}{l}\text { QOL-ACD-B ( } 3 \text { months after } \\
\text { treatment initiation) }\end{array}$ & Low/high & 1.077 & $0.555-2.040$ & 0.823 & & & \\
\hline $\begin{array}{l}\text { Change in QOL during } \\
\text { treatment }\end{array}$ & $\begin{array}{l}\text { Decrease or no } \\
\text { change/increase }\end{array}$ & 0.476 & $0.240-0.979$ & 0.044 & 0.686 & $0.303-1.577$ & 0.369 \\
\hline ORR & Non-responders/responders & 0.261 & $0.128-0.555$ & 0.001 & 0.328 & $0.141-0.789$ & 0.014 \\
\hline \multicolumn{8}{|l|}{ OS rate } \\
\hline Age at treatment & $\leq 65 />65$ years & 1.027 & $0.329-3.112$ & 0.962 & & & \\
\hline Tumor size & $\leq 39.4 />39.4 \mathrm{~mm}$ & 1.133 & $0.376-3.527$ & 0.822 & & & \\
\hline Skin infiltration & Negative/positive & 1.202 & $0.367-5.369$ & 0.776 & & & \\
\hline HER2 & Negative/positive & - & - & 0.124 & & & \\
\hline Ki67 & Negative/positive & 0.832 & $0.225-2.557$ & 0.757 & & & \\
\hline Lymph node metastasis & Negative/positive & 2.729 & $0.532-49.780$ & 0.269 & & & \\
\hline No. of metastatic organs & $\leq 2 / \geq 3$ & 3.206 & $0.959-9.745$ & 0.058 & 3.038 & $0.747-11.841$ & 0.116 \\
\hline Lung metastasis & Negative/positive & 0.646 & $0.210-2.045$ & 0.445 & & & \\
\hline Bone metastasis & Negative/positive & 1.965 & $0.621-7.440$ & 0.257 & & & \\
\hline Liver metastasis & Negative/positive & 4.115 & $0.889-14.540$ & 0.067 & 1.247 & $0.178-6.601$ & 0.811 \\
\hline Distant lymph node metastasis & Negative/positive & 1.239 & $0.373-3.724$ & 0.711 & & & \\
\hline Combined radiation therapy & No/yes & 2.008 & $0.108-11.022$ & 0.549 & & & \\
\hline QOL-ACD-B before treatment & Low/high & 0.650 & 0.176-1.997 & 0.462 & & & \\
\hline $\begin{array}{l}\text { QOL-ACD-B ( } 3 \text { months after } \\
\text { treatment initiation) }\end{array}$ & Low/high & 1.146 & $0.368-3.459$ & 0.872 & & & \\
\hline $\begin{array}{l}\text { Change in QOL during } \\
\text { treatment }\end{array}$ & $\begin{array}{l}\text { Decrease or no } \\
\text { change/increase }\end{array}$ & 0.464 & $0.154-1.443$ & 0.177 & & & \\
\hline ORR & Non-responders/responders & 0.257 & $0.084-0.808$ & 0.022 & 0.273 & $0.071-1.079$ & 0.063 \\
\hline
\end{tabular}

PFS, progression-free survival; OS, overall survival; HR, hazard ratio; CI, confidence interval; HER, human epidermal growth factor receptor; QOL, quality of life; QOL-ACD-B, Questionnaire for Cancer Patients Treated with Anti-Cancer Drugs-Breast.

significantly lower pre-treatment QOL-ACD-B score than the 'decreased QOL group' ( $\mathrm{P}=0.015$; Table III).

The 'increased QOL group' had a significant PFS rate extension when compared with the 'decreased QOL group' $(\mathrm{P}=0.032$; Fig. 2E). However, there was no significant difference in OS rate between the two groups $(\mathrm{P}=0.158$; Fig. $2 \mathrm{~F})$. In the univariate analysis of PFS rate, the 'increased QOL group' was found to have a significantly longer PFS rate $(\mathrm{HR}=0.476 ; 95 \% \mathrm{CI}$, 0.240-0.979; $\mathrm{P}=0.044)$. However, this association was not found to be statistically significant in multivariate analysis $(\mathrm{HR}=0.686$; 95\% CI, 0.303-1.577; $\mathrm{P}=0.369)$. In univariate and multivariate analyses of OS rate, neither QOL nor change in QOL was significantly associated with longer OS rate (Table IV).

\section{Discussion}

With the aging of society in recent years the number of elderly patients diagnosed with breast cancer has increased. In addition, 
the clinical features of breast cancer in the elderly differ from those in younger patients. For example, some studies have reported higher incidence of hormone-positive breast cancer, larger tumor size, fewer cases of lymph node metastases, and more frequent skin infiltrations in the elderly rather than the younger patients with breast cancer (11-14). As previously reported by our group, large tumors, lymph node metastases, and skin infiltrations resulted in deterioration of QOL in patients with breast cancer. In the present study, the QOL was analyzed in patients with advanced breast cancer undergoing hormonal therapy, and the results revealed no significant difference, based on any clinical features, including age.

Various studies have been conducted on the changes in the QOL during chemotherapy, with the majority reporting that QOL decreased within a few months following treatment (15-18). In the present study, it was shown that adverse reactions greatly decreased QOL scores in patients undergoing preoperative chemotherapy for breast cancer. There are also reports that the magnitude of the side effects varies depending on age (19-21). However, since this study included patients who underwent endocrine therapy, only a few patients had treatment-associated side effects. Therefore, a statistically significant improvement in QOL, due to the treatment, could be observed in most patients.

Although some studies have reported that chemotherapy led to mild deterioration of QOL in the elderly patients, the results of the present study are in accordance with numerous reports (including a meta-analysis of 10 studies) that have shown that age was not a predictor of QOL $(17,18,22-24)$. However, there was a significant age-based difference in the QOL score in the subcategory of 'Satisfaction with treatment and coping with disease'. Young subjects were more significantly affected by mental stress following diagnosis; however, their recovery thereafter was good, and they had the same QOL score as the elderly patients at 3 months after treatment initiation. These findings are similar to a previous study, in which little change was noted in the emotional status of elderly patients (17).

While QOL improved for a number of patients, it worsened for some others, and differences in clinical characteristics between these patient groups were observed. Patients with improved QOL had significantly larger tumor size and higher incidence of lymph node metastases, whereas no significant differences were observed in distant metastatic sites or the number of metastatic organs between the two groups. Additionally, those with improved QOL had significantly lower QOL prior to treatment initiation. Presumably, this is because the symptoms arising from a progressive primary breast cancer that decrease patient QOL score are alleviated by the endocrine treatment, leading to an improved QOL. Similar to previous reports, the patients of the present study with liver metastases or multiple organ metastases did not have a significantly worse prognosis, whereas patients who responded to endocrine therapy had a significantly better prognosis (25-27). Additionally, this study showed that the change in QOL during the 3 months after treatment initiation affected PFS rate. This is important since, according to other studies, the survival is prolonged by further improvements in QOL as a result of treatment $(15,28)$.

One of the limitations of the present study is the small sample size. Therefore, the median age of the cohort was used as the cut-off to create patient subgroups suitable for age-based comparisons. A small cohort is likely to be affected by various confounding factors. As shown in Table III, changes in QOL were significantly associated with tumor size, axillary lymph node metastasis and ORR. In particular, ORR had strong effects on both PFS rate and OS rate. In breast cancer with distant metastasis, it is clear that the response to treatment and the status of distant metastasis affect prognosis, and similar results are shown in this study. Changes in QOL score were found to have no significant effect on PFS rate in multivariate analysis, probably due to its association with ORR. However, ORR and QOL changes are not completely consistent. Furthermore, the QOL score may not be accurate, since it is a subjective evaluation. It is obvious that the QOL during treatment is influenced by the social position, family environment, and financial aspect. An examination of these parameters would facilitate comparisons with patients from other countries. Furthermore, QOL has been shown to change with treatment and to be affected by clinical factors. In the future, it would be important to consider factors, other than clinicopathological variables, and perform high-quality analysis based on them.

Taken together, psychological stress was more prominent in young patients with hormone receptor-positive breast cancer and distant metastases, who were treated with first-line endocrine therapy compared with elderly patients. Moreover, improving QOL within 3 months following treatment initiation could lead to longer PFS rate. Breast cancer with distant metastases is considered difficult to cure; hence the patient's QOL becomes more important when deciding upon a treatment plan. Young patients experience more psychological trauma during the diagnosis, and thus, the improvement of the patient's QOL should be an important consideration, since it may also have an impact on prognosis. Interestingly, some studies, albeit their small sample size, have reported that psychological support improved patient prognosis (29-31). The present study supports the importance of psychological care of patients, not only for the improvement of their QOL, but also for the improvement in prognosis.

\section{Acknowledgements}

The authors would like to thank Miss Yayoi Matsukiyo and Miss Tomomi Okawa (Data Manager, Department of Breast and Endocrine Surgery, Osaka City University Graduate School of Medicine) for the helpful advice regarding data management.

\section{Funding}

The study was supported by grants from the Japan Society for the Promotion of Science (KAKENHI) (grant nos. 19K18067, 26461957 and $17 \mathrm{~K} 10559)$ to SK. The funding agency had no role in the design, collection, analysis, interpretation of data or writing of this manuscript.

\section{Availability of data and materials}

The datasets used and/or analyzed during the present study are available from the corresponding author on reasonable request.

\section{Authors' contributions}

KoT participated in the design of the study and drafted the manuscript. SK participated in the design of the study and 
editing of the manuscript. YA, WG, TM, MS, RA and TT helped with study data collection and manuscript preparation. KaT and ST created T1-4 by aggregating the date, produced the figures and participated in the design of the study. $\mathrm{KH}$ and MO conceived the study, participated in the study design and coordination, and assisted with the drafting of the manuscript. All authors read and approved the final version of the manuscript.

\section{Ethics approval and consent to participate}

This study was conducted at Osaka City University Graduate School of Medicine in Osaka, Japan, according to the REMARK guidelines, following a retrospectively written research, pathological evaluation, and statistical plan (10). The study protocol was approved by the Ethics Committee of Osaka City University (approval no. 926). The research conformed to the provisions of the Declaration of Helsinki, 2013. All patients were informed of the investigational nature of the study and provided written, informed consent.

\section{Patient consent for publication}

Not applicable.

\section{Competing interest}

The authors declare that they have no competing interests.

\section{References}

1. Saracci R: The World Health Organisation needs to reconsider its definition of health. BMJ 314: 1409-1410, 1997.

2. Maisey NR, Norman A, Watson M, Allen MJ, Hill ME and Cunningham D: Baseline quality of life predicts survival in patients with advanced colorectal cancer. Eur J Cancer 38 1351-1357, 2002.

3. Kaasa S, Mastekaasa A and Lund E: Prognostic factors for patients with inoperable non-small cell lung cancer, limited disease. The importance of patients' subjective experience of disease and psychosocial well-being. Radiother Oncol 15: 235-242, 1989.

4. Gotay CC, Kawamoto CT, Bottomley A and Efficace F: The prognostic significance of patient-reported outcomes in cancer clinical trials. J Clin Oncol 26: 1355-1363, 2008.

5. Dancey J, Zee B, Osoba D, Whitehead M, Lu F, Kaizer L, Latreille J and Pater JL: Quality of life scores: An independent prognostic variable in a general population of cancer patients receiving chemotherapy. The National Cancer Institute of Canada Clinical Trials Group. Qual Life Res 6: 151-158, 1997.

6. Hortobagyi GN: Treatment of breast cancer. N Engl J Med 339: 974-984, 1998

7. McShane LM, Altman DG, Sauerbrei W, Taube SE, Gion M and Clark GM; Statistics Subcommittee of the NCI-EORTC Working Group on Cancer Diagnostics: Reporting recommendations for tumor marker prognostic studies (REMARK). J Natl Cancer Inst 97: 1180-1184, 2005.

8. Eisenhauer EA, Therasse P, Bogaerts J, Schwartz LH, Sargent D, Ford R, Dancey J, Arbuck S, Gwyther S, Mooney M, et al: New response evaluation criteria in solid tumours: Revised RECIST guideline (version 1.1). Eur J Cancer 45: 228-247, 2009.

9. Kurihara M, Shimizu H, Tsuboi K, Kobayashi K, Murakami M, Eguchi K and Shimozuma K: Development of quality of life questionnaire in Japan: Quality of life assessment of cancer patients receiving chemotherapy. Psychooncology 8: 355-363, 1999.

10. Otsuka S, Watanabe N, Sasaki Y and Shimojima R: Postoperative courses of breast reconstruction using inferior adipofascial tissue repair. Breast Cancer 22: 570-577, 2015.
11. Crivellari D, Aapro M, Leonard R, von Minckwitz G, Brain E, Goldhirsch A, Veronesi A and Muss H: Breast cancer in the elderly. J Clin Oncol 25: 1882-1890, 2007.

12. Louwman WJ, Vulto JC, Verhoeven RH, Nieuwenhuijzen GA, Coebergh JW and Voogd AC: Clinical epidemiology of breast cancer in the elderly. Eur J Cancer 43: 2242-2252, 2007.

13. Gennari R, Curigliano G, Rotmensz N, Robertson C, Colleoni M, Zurrida S, Nolè F, de Braud F, Orlando L, Leonardi MC, et al: Breast carcinoma in elderly women: Features of disease presentation, choice of local and systemic treatments compared with younger postmenopasual patients. Cancer 101: 1302-1310, 2004.

14. Wildiers H, Kunkler I, Biganzoli L, Fracheboud J, Vlastos G, Bernard-Marty C, Hurria A, Extermann M, Girre V, Brain E, et al: Management of breast cancer in elderly individuals: Recommendations of the International Society of Geriatric Oncology. Lancet Oncol 8: 1101-1115, 2007.

15. Shimozuma K, Sonoo H, Ichihara K and Tanaka K: The prognostic value of quality-of-life scores: Preliminary results of an analysis of patients with breast cancer. Surg Today 30: 255-261, 2000.

16. Schou I, Ekeberg O, Sandvik L, Hjermstad MJ and Ruland CM: Multiple predictors of health-related quality of life in early stage breast cancer. Data from a year follow-up study compared with the general population. Qual Life Res 14: 1813-1823, 2005.

17. Watters JM, Yau JC, O'Rourke K, Tomiak E and Gertler SZ: Functional status is well maintained in older women during adjuvant chemotherapy for breast cancer. Ann Oncol 14: 1744-1750, 2003.

18. Akin S, Can G, Durna Z and Aydiner A: The quality of life and self-efficacy of Turkish breast cancer patients undergoing chemotherapy. Eur J Oncol Nurs 12: 449-456, 2008.

19. Hurwitz N: Predisposing factors in adverse reactions to drugs. Br Med J 1: 536-539, 1969.

20. Cassidy J, Twelves C, Van Cutsem E, Hoff P, Bajetta E, Boyer M, Bugat R, Burger U, Garin A, Graeven U, et al: First-line oral capecitabine therapy in metastatic colorectal cancer: A favorable safety profile compared with intravenous 5-fluorouracil/leucovorin. Ann Oncol 13: 566-575, 2002.

21. Levy M,Kewitz H, Altwein W, Hillebrand J and Eliakim M: Hospital admissions due to adverse drug reactions: A comparative study from Jerusalem and Berlin. Eur J Clin Pharmacol 17: 25-31, 1980.

22. Hurria A, Hurria A, Zuckerman E, Panageas KS, Fornier M, D'Andrea G, Dang C, Moasser M, Robson M, Seidman A, et al: A prospective, longitudinal study of the functional status and quality of life of older patients with breast cancer receiving adjuvant chemotherapy. J Am Geriatr Soc 54: 1119-1124, 2006.

23. Mols F, Vingerhoets AJ, Coebergh JW and van de Poll-Franse LV: Quality of life among long-term breast cancer survivors: A systematic review. Eur J Cancer 41: 2613-2619, 2005.

24. Chee Chean D, Kuo Zang W, Lim M and Zulkefle N: Health Related Quality of Life (HRQoL) among breast cancer patients receiving chemotherapy in Hospital Melaka: Single Centre Experience. Asian Pac J Cancer Prev 17: 5121-5126, 2016.

25. Llombart-Cussac A, Pivot X, Biganzoli L, Cortes-Funes H, Pritchard KI, Pierga JY, Smith I, Thomssen C, Srock S, Sampayo $\mathrm{M}$ and Cortes J: A prognostic factor index for overall survival in patients receiving first-line chemotherapy for HER 2-negative advanced breast cancer: An analysis of the ATHENA trial. Breast 23: 656-662, 2014.

26. Dunphy FR, Spitzer G, Fornoff JE, Yau JC, Huan SD, Dicke KA, Buzdar AU and Hortobagyi GN: Factors predicting long-term survival for metastatic breast cancer patients treated with high-dose chemotherapy and bone marrow support. Cancer 73: 2157-2167, 1994.

27. Tsuji W, Teramukai S, Ueno M, Toi M and Inamoto T: Prognostic factors for survival after first recurrence in breast cancer: A retrospective analysis of 252 recurrent cases at a single institution. Breast Cancer 21: 86-95, 2014.

28. Coates A, Gebski V, Signorini D, Murray P, McNeil D, Byrne M and Forbes JF: Prognostic value of quality-of-life scores during chemotherapy for advanced breast cancer. Australian New Zealand Breast Cancer Trials Group. J Clin Oncol 10: 1833-1838, 1992

29. Spiegel D, Bloom JR, Kraemer HC and Gottheil E: Effect of psychosocial treatment on survival of patients with metastatic breast cancer. Lancet 2: 888-891, 1989.

30. Spiegel D, Sephton SE, Terr AI and Stites DP: Effects of psychosocial treatment in prolonging cancer survival may be mediated by neuroimmune pathways. Ann N Y Acad Sci 840: 674-683, 1998.

31. Kuchler T, Bestmann B, Rappat S, Henne-Bruns D and Wood-Dauphinee S: Impact of psychotherapeutic support for patients with gastrointestinal cancer undergoing surgery: 10-year survival results of a randomized trial. J Clin Oncol 25: 2702-2708, 2007. 